\title{
Integrating Interprofessional Education and Simulation in Community Health: Evaluation of a Practice-based Student Clinic
}

\author{
Jane Taylor* \\ Monash University, Australia \\ Mollie Burley \\ Monash University, Australia \\ Debra Nestel \\ Monash University, Australia
}

\begin{abstract}
There is an increasing need to deliver high quality integrated health services which address expanding numbers and increasing complexity of clients attending for health and social care. Despite demands to educate a future health care workforce with the capacity to deliver integrated team based services to meet these needs there is little in the literature about interprofessional education (IPE) in community health. We developed and evaluated a unique pilot simulated interprofessional student supervised clinic, integrated into the practice in a rural community health service. Pairs of students from two different disciplines interviewed a volunteer simulated client (SC) representing a real client case, and prepared a health care plan for the SC. Thematic analysis revealed overlap between the two groups. Both groups saw it as a positive experience. Students' responses to a questionnaire revealed they increased their client focus, interacted more with the other disciplines and found it highly realistic and authentic. Analysis of phone interviews with SCs confirmed the realism. SCs also saw it as supporting students' learning for the real world, and acknowledged the importance of support for themselves. This project confirms the perceived value of practice-based IPE with SCs from the perspectives of students and SCs in social care.
\end{abstract}

Keywords: interprofessional; practice-based; rural; simulation; social care

\section{Introduction}

There is an increasing need to deliver high quality health and social services which address expanding numbers and increasing complexity of clients attending for care. Additionally in Australia there is a significant gap in health and wellness between urban and rural communities (AlHW 2008). In response to this need in Australia there has been a push at national and state levels to develop interprofessional education (IPE) (National Health and Hospitals Reform Commission 2009, Garling 2008). In the last few years some increased but uneven progress has been made according to the most recent Australian reports (Mason 2013, Dunston et al. 2013).

There is a growing body of literature on IPE worldwide driven by the World Health Organisation (WHO 2010). Several systematic reviews identify various outcomes for IPE (Hammick et al. 2007, Reeves et al. 2010, and Zwarenstein et al. 1999) which include preparing individuals for collaborative practice; learning to work in teams; and developing services to improve care. IPE is being delivered in a variety of contexts and with models such as seminars, workshops and simulations (Reeves et al. 2011). A recent review which

${ }^{*}$ Corresponding Author: Jane Taylor, Monash University, Department of Rural and Indigenous Health, 3 Ollerton AvenueMoe, PO Box 973, Victoria, 3825, Australia Email: Jane.Taylor@monash.edu 94 
explored the factors instrumental to preparing and developing effective interprofessional clinical learning (IPCL) sites, found that an effective IPCL site needed a shared IPE culture, both at faculty (education institution) and in the health service organisation (Gum et al. 2012). One specific IPE model of interest to us is an interprofessional student clinic where students deliver collaborative health care. Canada has led the way with a number of student clinics suited to providing care in low socioeconomic areas such as in Edmonton (SHINE Youth Clinic) and Saskatchewan (SWITCH). In Australia, some student clinics and IPE student teams have been developed and run mainly in metropolitan areas by education institutions and in acute care settings (Matthews et al. 2011, Nisbet et al. 2008).

Rural communities are a suitable context for developing IPE as it has been argued that the workforce shortage creates the necessity to collaborate (Hays 2008) and this has been demonstrated in Australia where the rural and remote sector have led in IPE (Thistlethwaite 2007). North American rural exemplars such as mixed teams of students visiting Indian Reservations (Mu et al. 2004) reported on an increase in students' positive perceptions of IPE where teams of allied health students visited Indian reservations. In rural Australia, The Capricornia Project in Queensland (Frakes et al. 2011) provides an interprofessional student clinic. In addition, two more rural IPE projects: The Rural Interprofessional Project in Education (RIPE) in Victoria (McNair et al. 2005, Stone 2006); and the Rural Interprofessional Program Education Retreat (RIPPER) in Tasmania (Whelan et al. 2008), which placed mixed groups of disciplines in a rural setting, demonstrated outcomes of increased knowledge of others' roles.

Simulation techniques immerse students in experiences, mimic real practice and have been shown to promote collaboration and improve patient safety (Cleland et al. 2009, Kyrkjebo et al. 2006, and Murdoch et al. 2013). Recent reports of combined IPE/simulation team training using high fidelity mannequins (Shrader et al. 2013), standardised patients (Wamsley et al. 2012), or hybrid simulations (Shrader et al. 2013, Kilminster et al. 2004, and Vyas et al. 2012) suggest outcomes include improved understanding of roles of other professionals and increased awareness of the importance of interprofessional communication for patient safety. Further, Shrader et al. (2013) found that effective interprofessional teamwork is associated with positive clinical outcomes.

This article describes the development and evaluation of a unique model using simulation for IPE. The unique elements are the social care component, the community setting and the basing of simulated client (SC) roles on real client case histories. Our setting was Latrobe Community Health Service (LCHS) in Gippsland Victoria. We sought to offer health professional students on clinical placements in our health service the opportunity to experience interprofessional collaboration. We aimed to establish interprofessional clinics that would provide students an opportunity to 'learn with from and about each other' to improve quality of patient care (CAIPE 2002). However we encountered many challenges associated with the provision of this education, including the mismatch of placement blocks dictated by different education institutions, the relatively high numbers of students and the variety of year levels and health care disciplines, which rotate through LCHS all year through. There are challenges also in the high demands placed on the supervising Health Care Practitioners (HCPs) who could not be released to supervise and who have the responsibility to ensure their own students meet competency levels set by the education institutions while minimising disruption to the service, and maintaining care and safety of clients.

In order to fulfil our aims while meeting these challenges, our IPE was adapted to accommodate the health service needs. To overcome the lack of access to discipline specific supervisors within the health service, faculty consisted of one interprofessional supervisor (JT) from Monash University Department of Rural and Indigenous Health (MUDRIH) embedded in the health service. The competency levels required by different Higher Education Providers (HEPs) and registration bodies at present are not aligned and rarely cite IPE competencies specifically, but all list communication competencies and skills to various extents. To overcome this challenge we based our curriculum on basic IPE competencies (Hammick et al. 2009), and applied these to all disciplines. By running a generic intake interview, students' learning goals could be focused on communication and interview skills and client centred and holistic approaches, without recourse to assessing a variety of 
discipline specific competencies. For the purposes of the research, to avoid a possible bias of students responding 'to please examiners', the students were advised their performance in the student clinic would not contribute to their placement discipline assessment. To accommodate a broadly diverse student cohort with different timetables we paired two students from any two different disciplines to collaborate in intake interviews. The simulated student clinic operated in the midst of an active clinic, where different professions work partly side by side, and are usually less coordinated than the collaborative opportunities offered in simulation. However, it did provide an opportunity for the students to role model.

\section{Theoretical perspectives}

The literature on IPE identifies the need for securing a clear theoretical base (Clark 2006, Clark 2009, Barr 2013, and D'Amour et al. 2005). Being aware of the variety of models of health care teams, we were guided by the concept of teamwork as a dynamic process, involving two or more healthcare professionals with complementary backgrounds and skills sharing common goals and shared decision making (Xyrichis and Ream 2008).

Our educational design was informed by several theories. We wanted to provide experiential learning (Kolb and Fry 1975) enabling students to rehearse client-centred care (Stewart et al. 1995) before working in real community clinics. We valued the opportunity to encourage students to reflect on their prior experience in the light of their current and future interprofessional practice. Therefore, we drew on the opportunity for structured discussionbased reflection (Schon 1987, Clark 2009). Additionally we valued the notion of 'situated learning' in a 'Community of Practice' first proposed by Lave and Wenger (1991) and extended to embrace interactions in a joint enterprise characterised by mutual engagement and shared resources (Wenger 1998). A systematic review of communities of practice indicated that although complex and varied in nature they benefit health care practices (Ranmuthugala et al. 2011).

We wanted to maximise the benefits of experiencing IPE through the provision of purposively designed simulation scenarios with specific learning goals at times convenient for supervising HCPs to release their students. Critically, we wanted the opportunity to videotape and review practice with timely feedback from peers, faculty and the SCs. Scenarios needed to reflect existing practices and to focus on the increasing need for servicing a population of older ambulant clients with complex chronic conditions.

The broad aim of this paper is to share the evaluation of a simulated student clinic where students from different disciplines collaborated in pairs to assess SCs within the practice setting in a community health service, which emphasises holistic care in a psychosocial model of health. Specifically, in this paper we explore to what extent has participation in a student clinic with SCs enhanced the students' learning of interprofessional communication skills and attitudes.

\section{Methods}

Ethics approval was received from the Monash University Human Research Ethics Committee.

\section{Sampling}

Convenience sampling was used for the two study groups: group 1 students, group 2 SCs. The first group of students on placement at LCHS, whatever their health care discipline, were invited to participate. Twenty-six students volunteered to participate from eleven health care disciplines (See Figure 1). The second group of participants, the volunteer SCs, were invited to participate through the LCHS volunteer newsletter. Of the eight volunteer SCs who participated in the second group, two were members of staff with tertiary education, two were tertiary level students and the other four SCs were existing clients of LCHS. Local SC volunteers were given a $\$ 20.00$ petrol/grocery card. 


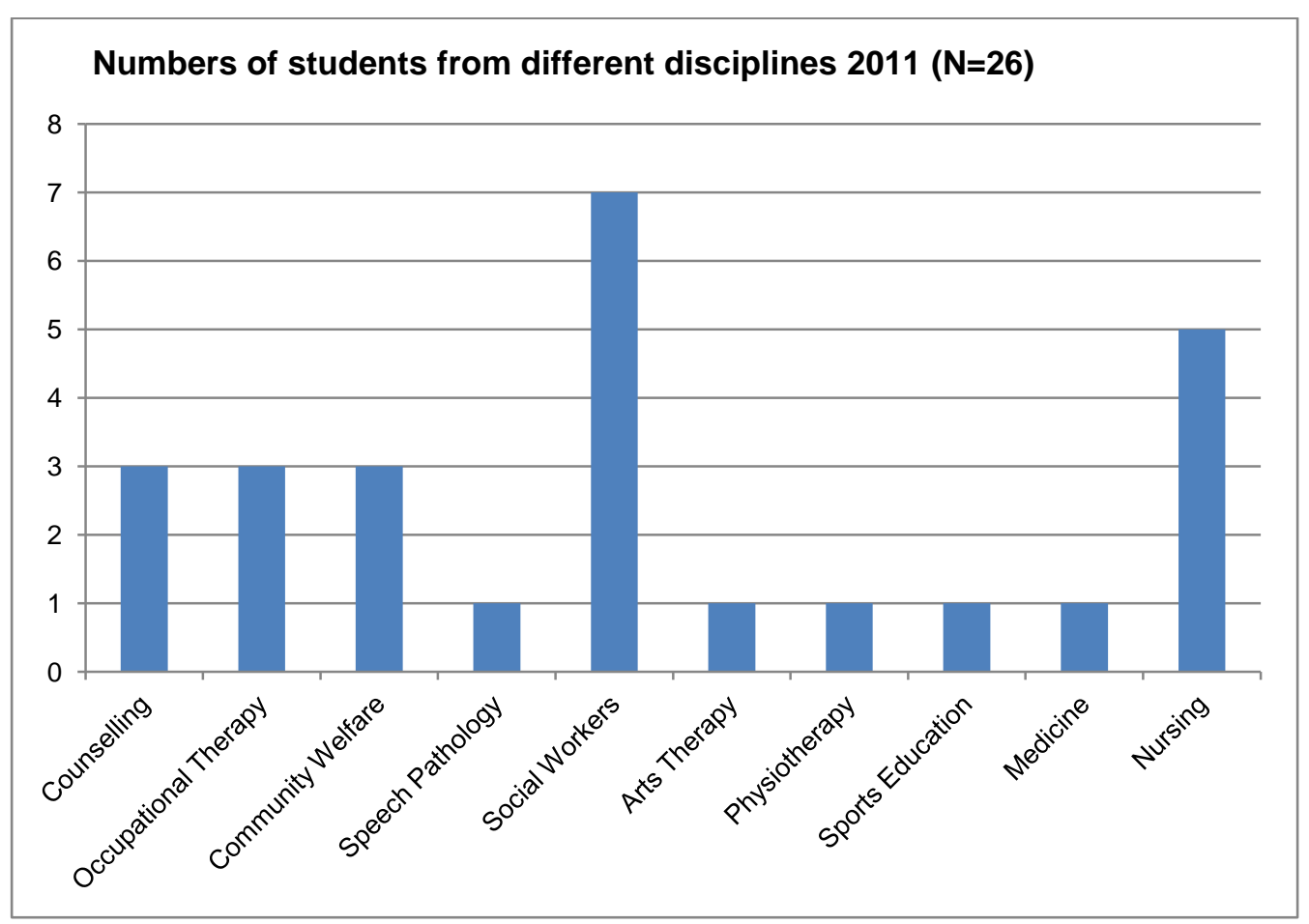

Figure 1. Integrating interprofessional education and simulation in community health: evaluation of a practice-based student clinic

\section{Education and support for SCs}

All of the SCs took part in two group education sessions with the addition of individual coaching from faculty. Key elements included: explaining the program, role portrayal and giving feedback. Eight genuine client cases with complex chronic conditions were selected from community health and the anonymised information was recorded on a character template for training SCs. Each SC was given a character template and they then worked in pairs to practice their role portrayal including visual effects (e.g. clothing, mobility aids). The SCs were also given the questions likely to be asked by students in order to plan answers in accordance with their character. Care for the emotional safety of the SCs was paramount. All members of faculty took it on board to check how SCs were coping with their roles, and ensuring they were 'de-roled' thoroughly. SCs were also given ongoing support such as follow up phone calls by faculty, to ensure they had not been impacted negatively by the difficult emotional aspects of the roles they played.

\section{Running the interprofessional student supervised clinic}

Once the simulated student clinic was opened, students were booked into small groups of four to six to maximise opportunities to collaborate with other disciplines. For the purposes of consistency in the pilot study this was a 'one-off' experience for students (see scenario outline in Table 2). Two SCs, each with a different character and scenario, were selected and booked to attend a four hour session. The selection of the interprofessional pairs was based on convenience, aiming to capture students with overlapping placements, with only the proviso that each student had the opportunity to work with another discipline. This could result in any combination (e.g. Medicine/Social Work, Nursing/Occupational Therapy). The activities in each session consisted of three phases: preparation; interviews; and feedback. All phases were conducted interprofessionally. Two scenarios were conducted in each clinic, where each pair of students took a turn as interviewers, and as active observers. 
Table 1. Excerpt from Simulated Interprofessional Clinic Scenario

\begin{tabular}{|c|c|}
\hline \multicolumn{2}{|l|}{ Scenario Protocol } \\
\hline Aim & $\begin{array}{l}\text { To develop a simulated clinic where health professional students } \\
\text { for two different disciplines collaborate to screen simulated clients } \\
\text { within the context and values of a community health service. }\end{array}$ \\
\hline Learning Objectives & $\begin{array}{l}\text { - Collaborate with a student from another discipline } \\
\text { - Conduct a client centred screening interview } \\
\text { - Complete a care plan for the client }\end{array}$ \\
\hline Scenario context & $\begin{array}{l}\text { Community "walk in" clinic. } \\
2 \text { Clients are attending, each for the first time for services. }\end{array}$ \\
\hline Setting & $\begin{array}{l}\text { The context for the simulation was a rural community health } \\
\text { service, which emphasises holistic client care within a psychosocial } \\
\text { model of health }\end{array}$ \\
\hline Session & $\begin{array}{l}\text { Each session lasted four hours and included two simulated } \\
\text { scenarios. The session was structured with three Interprofessional } \\
\text { education phases: Pre-briefing; two interviews; feedback (Including } \\
\text { video replay). }\end{array}$ \\
\hline $\begin{array}{l}\text { Technical /audiovisual } \\
\text { requirements }\end{array}$ & $\begin{array}{l}\text { The pilot was conducted with students and faculty observing } \\
\text { interviews live through a one-way screen or live audio-visual link. } \\
\text { Interviews were video-recorded and excerpts were replayed in the } \\
\text { feedback session. }\end{array}$ \\
\hline Faculty & $\begin{array}{l}\text { One interprofessional educator and one administrative technical } \\
\text { support person were required to run the session. }\end{array}$ \\
\hline Simulator & $\begin{array}{l}\text { Community volunteers were trained as simulated clients (SCs) to } \\
\text { portray authentic roles based on real client cases from the local } \\
\text { community. }\end{array}$ \\
\hline Target Participants & $\begin{array}{l}\text { Four-six students were invited to each session. Students from } \\
\text { different disciplines collaborated in pairs to conduct the interviews. } \\
\text { The students in the pilot program were drawn from different } \\
\text { universities across the following disciplines: Art Therapy; } \\
\text { Counselling; Community Welfare; Medicine; Nursing; Occupational } \\
\text { Therapy; Physiotherapy; Social Work; Speech Pathology; Sports } \\
\text { Education. }\end{array}$ \\
\hline
\end{tabular}

Prior to attending, students received pre-reading with information about the clinic, the learning objectives, the research, the nature of simulation, the interprofessional competencies needed to participate as well as pointers for holistic client-centred care, and best practice communication skills for team work. As a guide in the interview they were given an Interprofessional Referral Tool (IRT) designed by HCPs at LCHS to screen medical and psychosocial issues and list a care plan. At the clinic, students had 45 minutes of interprofessional briefing from faculty where they met each other, were then put into interdisciplinary pairs and were given time to share their background information, and each pair would collaborate on how they would conduct the interview.

In the interview scenario phase, each interdisciplinary pair of students met with a new 'walk-in client' in the busy active waiting area, and brought the SC to a normal consultation room. They then used the IRT to collaboratively interview the SC who was in character. The students completed the interview by suggesting a care plan and referrals for appropriate services. The interview was filmed and observed live externally by faculty and students. At the end of the interview the SC was 'de-roled' by faculty who then entered in the presence of the 
students. The students often witnessed quite a dramatic transformation as they then met the volunteer out of character.

The feedback phase was multilayered, commencing with feedback from the SC as themselves about how they had responded to the interview when in character. Once the SC departed, this was followed by comments from the observing peers about the collaboration of the interview pairs, their communication styles, and how they made the interview client centred. The SCs and the observers were all briefed in ways to give constructive feedback to the interviewing pairs and avoid what might be perceived as negative feedback. Some students initially expressed anxiety about being filmed, but their common response was they forgot about the cameras during the interview. The feedback session was completed with detailed group discussion with faculty which incorporated replay of selected parts of the video.

\section{Evaluation and Data collection process}

This enquiry took an interpretive approach (Angen 2000) chosen as the most coherent fit to investigate each participant's understanding of their world through the medium of free text in response to a questionnaire (students) and through spoken responses to a semi-structured phone interview (SCs). The data was analysed using a conceptual framework of thematic analysis (Miles and Huberman 1994, Green and Thorogood 2004). Immediately after the clinic activities, students completed a written questionnaire designed to evaluate their learning in general and specifically for IPC, their perceived realism of the SC and the scenario. All 26 students completed the questionnaire. Anonymised students' responses were transcribed and collated.

In the second study group, six of the eight SCs were interviewed individually by an independent researcher (MS) who used a topic guide to conduct telephone interviews after the program was completed. (Two SCs were unavailable). The interview explored SCs' overall impressions of the program and sought their feedback on specific issues such as their perception of students' responses to their feedback. (Interview protocols, questionnaires and topic guides are available on application.)

\section{Analysis}

Free text from the student questionnaires and the separate transcripts of SC interviews were analysed thematically from an interpretivist perspective. In both cases the chief investigator (JT) went backwards and forwards through the data in a reflexive manner comparing emergent themes. The second investigator (MB) who had not been directly involved with the clinic and the students provided peer review (Angen 2000) both in conversation about the themes and in reviewing the data.

\section{Results}

There were three major themes in the data for student and SC evaluations with some overlap between the two respondent groups. It was clear that both groups saw the experience as highly realistic and positive. While students made comments such as 'the experience was great' (S24), the SCs also reported it 'was fun' (SC1).

\section{Group 1, Students}

\section{Theme 1: Client focus}

The centrality of the client was a dominant theme combined with the need to look at the client holistically. Students learned more about the perspective of the client:

The client has always been at the centre of my learning and this experience highlighted the client's importance. The focus on the client is paramount. (S1) 
Holistic appreciation of client. (S5)

I just realized it's very important to dig deeper to encourage the client to talk about the issues they are facing. (S17)

Some students experienced the importance of balancing their own with the clients' needs:

Creating a balance between allowing a client to go at their own pace but also to ensure that discussions are kept on track without the client feeling unheard. (S8)

The students also reported gaining helpful insight about the client's perspective from the SCs' feedback:

[We] found reassurance from her that we were on the right track in her perception of feeling she was a person who was heard and respected. (S6)

\section{Theme 2: Interactions between disciplines}

Many students made comments which emphasised the Importance of an interdisciplinary team (S9), and of the collaborative process and rapport necessary for communicating with the other discipline. For example, students reported that they learned more about:

Communication and collaboration skills with another disciplinary team member. (S4)

Some learned about the balance of power:

Don't push your profession at the expense of others (S1).

Commonly, students highlighted how much they extended their awareness about the roles of other professionals and saw the benefits:

I felt that it was great to be able to draw on each other's knowledge base and that it assisted having a more thorough and balanced way of acquiring the information (S8)

Benefit of perspective from other professions (S9)

Theme 3: Realism and authenticity

Without exception, all students emphasised the realistic nature of the experience. This sense of realism was conveyed in a variety of ways, most commonly by the SC's portrayal of their character's symptoms:

The patient / client felt very realistic. This was achieved with both clothes, walking stick to the accent and words used. The issues that she presented with were situations that came across as genuine (S8).

Another factor contributing to the realism was the context of the scenario:

The scenario was quite realistic i.e.: being in consulting rooms, client resistive to referral. (S17)

\section{Group 2 Simulated Clients}

The SCs were consistently positive about their experience with no perceived negative impact on their enthusiasm from their differences in background and education level.

Theme 1: Supporting students' learning for the real world

All SCs made statements supporting their purpose in the clinic as providing relevant learning for relating to real people in the real world:

It's certainly got to be helpful for all the um, people that are learning to do their dealing with real people and all that sort of thing. (SC4) 
The SCs also saw safety as important, for both students and clients:

I think just giving people that ah, individual personalised time to um, um, feel free to try and get it right, but make mistakes in a, in a um, safe environment and ah, hopefully learn from it .(SC5)

Theme 2: Realism and authenticity

SCs' comments indicated it was important they portrayed a realistic character:

So they interview us, as the simulated patients, as if they are real patients so they get that, it feels genuine to them I guess. (SC3)

Some reported that they drew on their own experience to add realism to their character:

Yeah, Nar, I was able to draw on my own knowledge and experience. (SC6)

The sense that students found the characters convincing was underlined by their surprise when the SC was met out of role:

I think I was very realistic (Laughs).I think the student, um believed in in what I was portraying, um and I think they were very surprised to, once I was de-roled, to, to find that I was just a normal middle-aged person (SC6).

Theme 3: Importance of support for simulated clients

Irrespective of the SCs' backgrounds, SCs reported how important it was for them to have support from faculty, not only in the training and character development but also in providing control and safety.

One SC commented:

What worked well was um, (the IP supervisor) keeping an eye on the situation, so in case the simulated client gets too involved, they'll be able to break it up. (SC1)

Another SC added:

It could have been um daunting ah, for, um, simulated patients to, to provide useful feedback, but the fact that (the IP supervisor) was there when I was giving feedback, and could in a sense um, help me direct the feedback to relevant parts of the interview was useful. (SC3)

A further comment illustrated the SC's perception of the importance of support from faculty for ensuring emotional separation from the SC character:

It had come fairly close to ah me as an individual [...] to make it realistic. But not close enough so that um I found it um intimidating [...] um [...] and (IP Supervisor) and I re-tuned the role [...] so that I didn't run the risk of being overwhelmed. (SC3)

\section{Discussion}

This project addressed the WHO (2010) recommendation to provide health professional students with experiences in collaborating within the practice of health service, and is responsive to Australian government initiatives to improve working in teams (Mason 2013, LTIPP 2009). It was clear from the analysis of the students' questionnaires and the phone interviews with the SCs that both students and volunteer SCs were overwhelmingly positive about the experience. Students learnt more about the roles of other disciplines, and saw the importance of collaborating with other disciplines. These findings were consistent with 
outcomes outlined in previous systematic reviews of IPE (Reeves et al. 2010, Hammick et al. 2007)

The strength of this project lay with a number of design features and outcomes. Firstly, we were mindful of the increase in numbers of older age clients with chronic conditions (Bodenheimer et al. 2002). Our study design addressed the need outlined in the Garling Report (Garling 2008) to provide these clients with effective holistic client centred care by deliberately developing eight simulation scenarios selected from actual cases of social care clients with complex chronic conditions. More specifically, our project combined IPE with scenario-based education (SBE) and as such our results might be more closely compared with more recent studies of IPE programs developed by HEPS which have similarly utilised SBE to deliver IPE programs for undergraduates (Shrader et al. 2013, Kyrkjebo et al. 2006, Vyas et al. 2012, Wamsley et al. 2012, and Kilminster et al. 2004). Our study was different in respect of the use of volunteer SCs, the rural setting in community health, and the pairing of different disciplines to collaborate in a simulated intake interview. Our students similarly saw the benefits of working in interprofessional teams and strongly expressed raised awareness of the breadth and range of knowledge of other health disciplines. Our study design advanced knowledge in several important respects: we provided for a wider range of eleven health care disciplines; our students collaborated in mixed pairs to co-interview the SCs; our simulations were delivered within the context of an active rural community health service; and students were drawn from a range of education providers rather than from one institution.

Our results were also in line with previous literature reviews which indicated that authenticity adds to the strength of the IPE simulation experience (Hammick et al. 2007). Our study design endeavoured to increase authenticity by customising elements to closely match the typical client journey by having students meet their SCs in busy waiting rooms, and conduct their interview in consulting rooms side-by-side with active practitioners. Students' comments indicated that the overall positive experience was due to the realism of the practice context as well as to the authenticity of the SCs stories and their body language in presentation of their characters.

There are limitations to the study because of the small sample size which restricts generalisability of results. Students were largely self-selected and so the outcomes may not be relevant to all students. Student evaluation forms were collected immediately after the clinics and so may not reflect lasting impact. However, the SCs were surveyed many months after the experience and still reported very positive experiences. The two SCs who were not interviewed may not have had experiences as positive as those reported by their peers. Further, the results are self-report and do not reflect changes in actual practice.

At LCHS we have built on this project by extending the student tasks in the clinic to include co-management of actual clients and increased the range of disciplines involved in the ongoing program. Education providers are seeking placements for their students at LCHS because they are aware of IPE opportunities. The model has since been replicated in five sites across Gippsland in both acute and community health practice settings. The research could be further developed to evaluate the impact on service delivery and to obtain the perspectives of supervisors and to follow students up in practice.

\section{Conclusion}

We successfully developed, delivered and evaluated an innovative model of a simulated student clinic where interprofessional pairs of students from eleven different disciplines interviewed volunteer SCs within a rural community health care practice setting. In this pilot project we have established effective IPE where students learned, with, from and about each other (CAIPE 2002) by using an authentic and realistic simulation scenario in social care. Although this project confirms the perceived value of IPE with SCs from the perspectives of both students and SCs, the small sample limits generalisation of the results. 


\section{Acknowledgments}

The authors extend thanks to the following: Department of Health Victoria who provided a seeding grant to fund this pilot project; Mitchell Smith (MS) who carried out research interviews and transcriptions; Fiona McCook who advised on educational aspects and Dr. Anske Robinson who provided editing advice. 


\section{References}

AlHW (2008) Rural, regional and remote health: indicators of health status and determinants of health. Canberra: Australian Institute of Health and Welfare

Angen, M. J. (2000) 'Evaluating interpretive inquiry: reviewing the validity debate and opening the dialogue'. Qualitative Health Research 10, 378-95

Barr, H. (2013) 'Toward a theoretical framework for interprofessional education'. Journal of Interprofessional Care 27, 4-9

Bodenheimer, T., Wagner, E. H., and Grumbach, K. (2002) 'Improving primary care for patients with chronic illness' JAMA 288, 1775-9

CAIPE (2002) Centre for the Advancement of Interprofessional Education [online] available from <caipe.org.uk> [18 February 2014]

Clark, P. G. (2006) 'What would a theory of interprofessional education look like? Some suggestions for developing a theoretical framework for teamwork training'. Journal of Interprofessional Care 20, 577-589

Clark, P. G. (2009) 'Reflecting on reflection in interprofessional education: Implications for theory and practice'. Journal of Interprofessional Care 23, 213-223

Cleland, J. A., Abe, K., and Rethans, J. (2009) 'The use of simulated clients in medical education: AMEE Guide No. 31'. Medical Teacher 42, 477-486

D'amour, D., Ferrada-Videla, M., San Martin Rodriguez, L., and Beaulieu, M. (2005) 'The conceptual basis for interprofessional collaboration: Core concepts and theoretical frameworks'. Journal of Interprofessional Care 19, 116-131

Dunston, R., Forman, D., Rogers, G., and Thistlethwaite, J. (2013) Interprofessional Education: a National Audit. Report to Health Workforce Australia. The Interprofessional Curriculum Renewal Consortium Australia [online] available from <http://www.hwa.gov.au/sites/uploads/IPE\%20Audit\%20report\%20Jan\%202013.pdf> [28 May 2015]

Frakes, K., Tyack, Z.F., Miller, M., Davies, L., Swanston, A. and Brownie, S. (2011) The Capricornia Project: Developing and implementing an interprofessional studentassisted allied health clinic. Brisbane, Australia: Queensland Health

Garling, P. (2008) Final Report of the Special Commission of Inquiry. Acute Care Services in NSW Public Hospitals [online] available from $<<$ http://www.dpc.nsw.gov.au/_data/assets/pdf_file/0003/34194/Overview__Special_Commission_Of_Inquiry_Into_Acute_Care_Services_In_New_South_Wale S_Public_Hospitals.pdf> [28 May 2015]

Green, J., and Thorogood, N. (2004) Qualitiative Methods for Health Research. London: Sage.

Gum, L. F., Richards, J., Bradley, S. L., Lindeman, I., Ward, H. M. and Bennett, P. (2012) 'Preparing the interprofessional clinical learning sites: What the literature tells us'. Focus on Health Professional Education: A multidisciplinary Journal 13(3), 55-70

Hammick, M., Freeth, D., Copperman, J., and Goodman, D. (2009) Being Interprofessional. Cambridge: Polity Press 
Hammick, M., Freeth, D., Koppel, I., Reeves, S. and Barr, H. (2007) 'A best evidence systematic review of interprofessional education: BEME Guide no. 9' Medical Teacher $29,735-751$

Hays, R. B. (2008) 'Interprofessional education in rural practice: how, when and where?' Rural \& Remote Health 8, 939

Kilminster, S., Hale, C., Lascelles, M., Morris, P., Roberts, T., Stark, P., Sowter, J., and Thistlethwaite, J. (2004) 'Learning for real life: Patient-focused interprofessional workshops offer added value' Medical Education 38, 717-726

Kolb, D. and Fry, R. (1975) 'Toward an applied theory of experiential learning'. in Theories of Group Process. ed. by Cooper, C. London: John Wiley

Kyrkjebo, J. M., Brattebo, G. and Smith-Strom, H. (2006) 'Improving patient safety by using interprofessional simulation training in health professional education'. Journal of Interprofessional Care 20, 507-516

L-TIPP (2009) Interprofessional Education in Australia:The Way Forward. Sydney: Australian Learning and Teaching Council

Lave, J., and Wenger, E. (1991) Situated Learning: Legitimate peripheral participation. Cambridge: Cambridge University Press

LCHS (n. d.) Latrobe Community Health Service [online] available from <www.lchs.com.au> [29 November 2014]

Mason, J. (2013) Review of Australian Government Health Workforce Programs. Australian Federal Government. [online] available from <http://www.health.gov.au/internet/main/publishing.nsf/Content/D26858F4B68834EA CA257BF0001A8DDC/\$File/Review\%20of\%20Health\%20Workforce\%20programs. pdf> [28 May 2015]

Matthews, L. R., Pockett, R. B., Nisbet, G., Thistlethwaite, J. E., Dunston, R., Lee, A., and White, J. F. (2011) 'Building capacity in Australian interprofessional health education: Perspectives from key health and higher education stakeholders'. Australian Health Review 35, 136-140

Mcnair, R., Stone, N., Sims, J., and Curtis, C. (2005) 'Australian evidence for interprofessional education contributing to effective teamwork preparation and interest in rural practice'. Journal of Interprofessional Care 19, 579-594

Miles, M. B. and Huberman, A. M. (1994) Qualitative Data Analysis: an Expanded Sourcebook. London: Sage

Mu, K., Chao, C., Jensen, G. M. and Royeen, C. B. (2004) 'Effects of Interprofessional Rural Training on Students' Perceptions of Interprofessional Health Care Services'. Journal of Allied Health 33, 125-131

MUDRIH (n.d.) Monash University Department of Rural and Indigenous Health [online] available from< http://www.med.monash.edu.au/srh/mudrih/> [30 November 2014]

Murdoch, N. L., Bottorff, J. L., and Mc Cullough, D. (2013) 'Simulation Education Approaches to Enhance Collaborative Health Care: A Best Practices Review' International Journal of Nursing Education Scholarship 10, 307-321

National Health and Hospitals Reform Commission (2009) A Healthier Future for all Australians- Final Report [online] available from 
$<$ http://www.health.gov.au/internet/nhhrc/publishing.nsf/content/nhhrc-report> [28 May 2015]

Nisbet, G., Hendry, G. D., Nolls, G., and Field, M. J. (2008) 'Interprofessional Learning for prequalification health care students: an outcomes based evaluation' Journal of Interprofessional Care 22, 57-68

Ranmuthugala, G., Plumb, J., Cunningham, F., Georgiou, A., Westbrook, J., and Braithwaite, J. (2011) 'How and why are communities of practice established in the health care sector? A systematic review of the literature'. BioMedCentral 11, 1472-6963

Reeves, S., Goldman, J., Gilbert, J., Tepper, J., Silver, I., Suter, E., and Zwarenstein, M. (2011) 'A scoping review to improve conceptual clarity of interprofessional interventions'. Journal of Interprofessional Care 25, 167-174

Reeves, S., Zwarenstein, M., Goldman, J., Barr, H., Freeth, D., Koppel, I., and Hammick, M. (2010) 'The effectiveness of interprofessional education: Key findings from a new systematic review'. Journal of Interprofessional Care 24, 230-241

Schon, D. (1987) Educating the Reflective Practitioner. San Francisco: Jossey-Bass

SHINE Youth Clinic (n.d.) Student Health Initiative for the Needs for Edmonton_SHINE Edmonton: University of Alberta. [online] available from<http://www.shineclinic.ca> [09 February 2014]

Shrader, S., Kern, D., Zoller, J., and Blue, A. (2013) 'Interprofessional teamwork skills as predictors of clinical outcomes in a simulated health care setting'. Journal of Allied Health 42(1), e1-6

Stewart, M., Brown, J., Weston, W., Mcwhinney, I., Mcwilliam, C., and Freeman, T. (1995) Patient-Centred Medicine. Transforming the Clinical Method. London: Sage

Stone, N. (2006) The Rural Interprofessional Education Project (RIPE). Journal of Interprofessional Care 20, 79-81

SWITCH (2005) Student Wellness Initiative Toward Community Health_SWITCH. Saskatchewan, Canada: University of Saskatchewan. [online] available from $<$ www.SWITCH.usask.ca> [09 February 2014]

Thistlethwaite, J. (2007) 'Interprofessional Education in Australasia'. Journal of Interprofessional Care 21(4), 369-372

Vyas, D., Mcculloh, R., Dyer, C., Gregory, G., and Higbee, D. (2012) 'An Interprofessional course using human patient simulation to teach patient safety and teamwork skills'. American Journal of Pharmaceutical Education 76(4), 71

Wamsley, M., Staves, J., Kroon, L. A., Topp, K., Hossaini, M., Newlin, B., Lindsay, C., and O'Brien, B. (2012) 'The impact of an interprofessional standardized patient exercise on attitudes towards working in interprofessional teams'. Journal of Interprofessional Care 26, 28-35

Wenger, E. (1998) Communities of Practice: Learning, meaning and identity. Cambridge: Cambridge University Press

Whelan, J. J., Spencer, J. F., and Rooney, K. (2008) 'A 'RIPPER' Project: advancing rural inter-professional health education at the University of Tasmania'. Rural and Remote Health 8, 1017 
World Health Organisation (2010) 'Framework for action on interprofessional education and collaborative practice' [online] available from

<http://www.who.int/hrh/resources/framework_action/en/> [28 May 2015]

Xyrichis, A., and Ream, E. (2008) 'Teamwork: a concept analysis'. Journal of Advanced Nursing $61,232-241$

Zwarenstein, M., Atkins, J., Barr, H., Hammick, R., Koppel, I., and Reeves, S. (1999) 'A systematic review of interprofessional education' Journal of Interprofessional Care 13, 417-424 